\title{
VOLTERRA TYPE OPERATORS ON MORREY TYPE SPACES
}

\section{RUISHEN QIAN AND SONGXIAO Li}

Abstract. In this paper, we investigate the boundedness of Volterra type operators on Morrey type spaces $H_{K}^{2}$.

Mathematics subject classification (2010): 30H25, 47B38.

Keywords and phrases: Morrey type space, $Q_{K}$ space, Volterra type operator.

\section{REFERENCES}

[1] A. Aleman And J. Cima, An integral operator on $H^{p}$ and Hardy's inequality, J. Anal. Math. 85 (2001), 157-176.

[2] K. Avetisyan And S. Stević, Extended Cesàro operators between different Hardy spaces, Appl. Math. Comput. 207 (2009), 346-350.

[3] D. Chang, S. Li AND S. STEVIĆ, On some integral operators on the unit polydisk and the unit ball, Taiwanese J. Math. 11 (2007), 1251-1286.

[4] M. EssÉN AND H. WULAN, On analytic and meromorphic functions and spaces of $Q_{K}$-type, Illinois J. Math. 46 (2002), 1233-1258.

[5] M. EsSÉn, H. Wulan AND J. XIAO, Several function-theoretic characterizations of Möbius invariant $Q_{K}$ spaces, J. Funct. Anal. 230 (2006), 78-115.

[6] J. Garnett, Bounded Analytic Functions, Academic Press, New York, 1981.

[7] Z. Hu, Extended Cesàro operators on mixed norm spaces, Proc. Amer. Math. Soc. 131 (2003), 21712179.

[8] S. Krantz And S. Stević, On the iterated logarithmic Bloch space on the unit ball, Nonlinear Anal. TMA 71 (2009), 1772-1795.

[9] S. LI, Riemann-Stieltjes operators from $F(p, q, s)$ to Bloch space on the unit ball, J. Ineq. Appl. 2006, Article ID 27874, (2006), Pages 1-14.

[10] P. LI, J. LiU AND Z. LoU, Integral operators on analytic Morrey spaces, Sci. China 57 (2014), 1-15.

[11] S. Li AND S. STEVIĆ, Integral type operators from mixed-norm spaces to $\alpha$-Bloch spaces, Integral Transforms Spec. Funct. 18 (7) (2007), 485-493.

[12] S. Li AND S. STEVIĆ, Generalized composition operators on Zygmund spaces and Bloch type spaces, J. Math. Anal. Appl. 338 (2008), 1282-1295.

[13] S. Li AND S. STEVIĆ, Riemann-Stieltjes operators between different weighted Bergman spaces, Bull. Belg. Math. Soc. Simon Stevin, 15 (2008), 677-686.

[14] S. Li AND S. STEvić, Cesàro type operators on some spaces of analytic functions on the unit ball, Appl. Math. Comput. 208 (2009), 378-388.

[15] S. Li AND S. STEVIĆ, Integral-type operators from Bloch-type spaces to Zygmund-type spaces, Appl. Math. Comput. 215 (2009), 464-473.

[16] C. Morrey, On the solutions of quasi-linear elliptic partial differential equations, Trans. Amer. Math. Soc. 43 (1938), 126-166.

[17] C. PAN, On an integral-type operator from $Q_{K}(p, q)$ spaces to $\alpha$-Bloch space, Filomat, 25 (2011), 163-173.

[18] C. Pommerenke, Schlichte funktionen und analytische funktionen von beschränkter mittlerer oszillation, Comment. Math. Helv. 52 (1977), 591-602.

[19] A. Siskakis AND R. ZhaO, A Volterra type operator on spaces of analytic functions, Contemp. Math. 232 (1999), 299-311. 
[20] S. STEvić, On a new integral-type operator from the Bloch space to Bloch-type spaces on the unit ball, J. Math. Anal. Appl. 354 (2009), 426-434.

[21] S. STEvić, On an integral-type operator from logarithmic Bloch-type and mixed-norm spaces to Bloch-type spaces, Nonlinear Anal. TMA 71 (2009), 6323-6342.

[22] S. STEVIĆ, Products of integral-type operators and composition operators from the mixed norm space to Bloch-type spaces, Siberian Math. J. 50 (4) (2009), 726-736.

[23] S. STEVIĆ, On an integral operator between Bloch-type spaces on the unit ball, Bull. Sci. Math. 134 (2010), 329-339.

[24] S. STEVIĆ AND S. UeKI, Integral-type operators acting between weighted-type spaces on the unit ball, Appl. Math. Comput. 215 (2009), 2464-2471.

[25] X. TANG, Extended Cesàro operators between Bloch-type spaces in the unit ball of $\mathbb{C}^{n}$, J. Math. Anal. Appl. 326 (2007), 1199-1211.

[26] Z. Wu AND C. XIE, $Q$ space and Morrey spaces, J. Funct. Anal. 201 (2003), 282-297.

[27] H. Wulan and J. Zhou, $Q_{K}$ and Morrey type spaces, Ann. Acad. Sci. Fenn. Math. 38 (2013), 193-207.

[28] J. XIAO, Holomorphic Q Classes, Springer, LNM 1767, Berlin, 2001.

[29] J. XIAO, Riemann-Stieltjes operators on weighted Bloch and Bergman spaces of the unit ball, J. London. Math. Soc. 70 (2) (2004), 199-214.

[30] R. ZhaO, Distances from Bloch functions to some Möbius invariant spaces, Ann. Acad. Sci. Fenn. Math. 33 (2008), 303-313.

[31] K. ZHU, Operator Theory in Function Spaces, American Mathematical Society, Providence, RI, 2007.

[32] X. ZHU, Volterra composition operators on logarithmic Bloch spaces, Banach J. Math. Anal. 3 (2009), $122-130$.

[33] X. ZHU, Volterra composition operators from generalized weighted Bergman spaces to $\mu$-Bloch type spaces, J. Funct. Space Appl. 7 (2009), 225-240. 